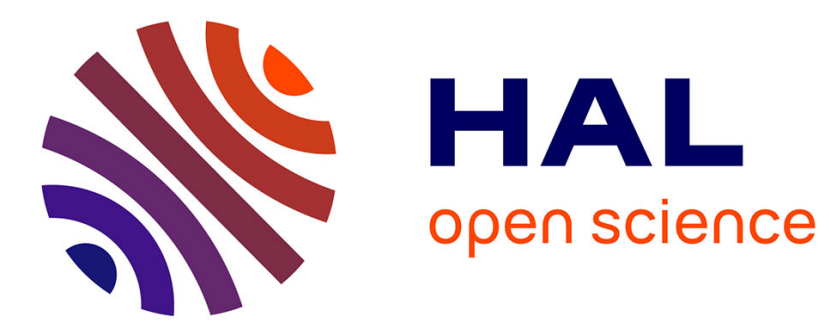

\title{
Permeability and porosity improvement of grouted sand
} Nadia Saiyouri, Abdelghafour Ait Alaiwa, Pierre-Yves Hicher

\section{To cite this version:}

Nadia Saiyouri, Abdelghafour Aït Alaiwa, Pierre-Yves Hicher. Permeability and porosity improvement of grouted sand. European Journal of Environmental and Civil Engineering, 2011, 15 (3), pp.77-97. 10.3166/EJECE.15.313-333 . hal-01007182

\section{HAL Id: hal-01007182 \\ https://hal.science/hal-01007182}

Submitted on 18 Jan 2017

HAL is a multi-disciplinary open access archive for the deposit and dissemination of scientific research documents, whether they are published or not. The documents may come from teaching and research institutions in France or abroad, or from public or private research centers.
L'archive ouverte pluridisciplinaire HAL, est destinée au dépôt et à la diffusion de documents scientifiques de niveau recherche, publiés ou non, émanant des établissements d'enseignement et de recherche français ou étrangers, des laboratoires publics ou privés.

\section{(c)(1)}

Distributed under a Creative Commons Attribution| 4.0 International License 


\section{Permeability and porosity improvement of grouted sand}

\section{Nadia Saiyouri - Abdelghafour Ait Alaiwa Pierre Yves Hicher}

Research Institute of Civil and Mechanical Engineering (GeM), UMR CNRS 6183

Ecole Centrale de Nantes, 1 rue de la Noë, F-44321 Nantes cedex 3

Nadia.saiyouri@ec-nantes.fr

ABSTRACT. Over the past twenty years, grouting technology allowed to treat a wide range of subsurface conditions for construction. When a properly designed cement grout is injected into sand soil, homogeneous grout bulbs are formed which make dense and thus strengthen the surrounding soil. For successful grouting, the knowledge of subsurface conditions is important. Ground improvement can be assessed by permeability testing and mercury porosimetry testing. Laboratory experiments were conducted to examine grout injection through Loire sand columns under saturated conditions. These tests were performed in order to highlight the effect of some key factors: cement-to-water ratio, relative density of the granular skeleton on the properties of the grouted sand. Subsequently Mercury Intrusion Porosimetry tests showed that both porosity and its distribution are modified. Besides, the intrinsic permeability was measured by a gas permeability device. Then, an evaluation of intrinsic permeability using the Katz-Thompson equation on these tests is proposed and compared to gas permeability which is still commonly used in civil engineering to measure this intrinsic parameter.

RÉSUMÉ. Pendant les vingt dernières années, la technologie de l'injection des sols a permis de traiter un grand nombre de terrains pour une bonne préparation à la construction. Quand un coulis de ciment correctement conçu est injecté dans un sable, des bulbes d'injection sont formés ce qui densifie et renforce ainsi le sol environnant. Pour réussir l'opération d'injection, la connaissance des conditions du sous-sol est importante. L'amélioration des sols injectés peut être évaluée par des tests de perméabilité et de porosimétrie par intrusion de mercure. Des expériences de laboratoire ont été conduites pour examiner l'injection de coulis dans des colonnes de sable de Loire dans des conditions saturées. Ces essais ont été exécutés pour mettre en évidence l'effet de quelques facteurs clefs : proportion de ciment-eau, densité relative du squelette granulaire sur les propriétés du sable injecté. Par la suite, les essais de porosimétrie mercure ont montré que tant la porosité que sa distribution sont modifiées. En plus, la perméabilité intrinsèque a été mesurée par un dispositif de perméabilité au gaz. On propose ensuite une évaluation de la perméabilité intrinsèque utilisant l'équation Katz-Thompson sur ces essais qui est comparée à la perméabilité au gaz qui est généralement utilisée en génie civil pour mesurer ce paramètre intrinsèque.

KEYWORDS: cement, injection, permeability, porosimetry, soil.

MOTS-CLÉS : ciment, injection, perméabilité, porosimétrie, sol. 


\section{Introduction}

Grouting is the most common technical method which is used for soil stabilization and strengthening, for soil permeation (Cambefort, 1937). This technique has a wide application in modern civil engineering world (Nonveiller 1989). It can be employed to reduce permeability of a ground mass formation in order to control seepage and loss of stored water. One of these techniques is cement grout injection process (Arenzana, 1987; Zebovitz et al., 1989; Schwarz, 1997). This treatment consists in introducing under pressure, through a sleeve pipe, various materials intended to fill the void space available in the soil. To evaluate the effectiveness of this operation, the intrinsic permeability coefficient $(\mathrm{Kv})$ is measured. In soil mechanics, water permeability measurements are generally carried out. This test consists in saturating a sample with water, then applying constant water head on this sample. After that, measurements are performed to quantify the water crossing the specimen when the flow is steady.

For the injected grounds, this method, also available, is more complicated because their relatively low permeability makes testing with water very time consuming (Saiyouri et al., 2007). Besides, a high water pressure must be applied to obtain measurable flows, which can damage the studied medium. To avoid this difficulty, we selected gas permeability using gases such as oxygen or nitrogen. A number of laboratory based tests have been developed to measure the gas permeability of concrete and mortars, including the Cembureau test (Verdier and Carcassès, 2002; Kollek, 1989; Abbas et al., 1999). The pressure cell method (Martin, 1986) and the Leeds permeability cell (Cabrera and Lynsdale, 1988). Insitu tests have also been developed (Claisse et al., 2003; Figg 1973; Basheer et al., 1994; Dhir et al., 1995). Further, in soil mechanics, permeability tests for cored samples using gases have become standard (American Petroleum Institute, 1956; AFREM, 1996; ASTM, 2004). However no attempts to evaluate permeability of grouted sand using this method was carried out because of difficult preconditioning procedures.

The aim of the work presented in this paper was to develop experimental procedures to evaluate the intrinsic permeability from Cembureau measurements initially dedicated to homogeneous cement based materials on cylindrical grouted sand specimens and measure the samples porosities by Mercury Intrusion Porosimetry tests (MIP). It is of significant interest to relate the permeabilities of cementitious materials to parameters that control the development of microstructure. As a consequence, a variety of investigations have been carried out to elucidate possible relationships between pore structures and permeability in these materials. On the basis of the experiments, empirical relationships between characteristics of the media (e.g. permeability and porosity) can be established to study the effect of grouting process on non-uniform soil structures although natural granular soils, in most cases, consist of non uniform particles. Therefore studies of gas permeability which quickly allowed us to evaluate the intrinsic coefficient of permeability $\mathrm{Kv}$ 
associated to useful MIP results to estimate the order of magnitude of this transfer parameter thanks to a modified Katz-Thompson formulation, applicable to cement based materials, are essential from a practical point of view. Indeed, transfer property plays an important role in durability of reinforced soil. Besides, this coefficient depends on several parameters which will be discussed.

\section{Materials and methods}

\subsection{Experimental program}

\subsubsection{Soil column samples}

For this study, cylinders with $90 \mathrm{~cm}$ of length and $10 \mathrm{~cm}$ of diameter at different densities were filled up with dry Loire sand. This sand is a poorly graded sand (SP); its characteristics are given in Table 1 .

Table 1. Loire sand parameters (NFP 94-056)

\begin{tabular}{|c|c|c|c|c|c|}
\hline$D_{30}(\mu \mathrm{m})$ & $D_{50}(\mu \mathrm{m})$ & $D_{60}(\mu \mathrm{m})$ & $\mathrm{Cu}$ & $\mathrm{Cs}$ & $\gamma_{\mathrm{s}}\left(\mathrm{KN} / \mathrm{m}^{3}\right)$ \\
\hline 320 & 520 & 670 & 3,53 & 0,8 & 26,2 \\
\hline
\end{tabular}

\subsubsection{Grout properties}

The grouts used in the tests contain Spinor A12 ${ }^{\circledR}$ ultrafine cement. Prepared grouts with Cement/Water ratios $(\mathrm{C} / \mathrm{W}) 0.28$ and 0.42 were injected into the soil samples. They were prepared in a bowl and then mixed for 10 min using a mixer at a speed of $1000 \mathrm{rpm}$. Superplasticizer Sikament FF86 manufacyured by SIKA $\AA, 3 \%$ by weight of dry cement was added to the cement-water mixtures, in order to increase the grout fluidity an inert component was also incorporated to improve rheological stability of the mixture.

\subsubsection{Experimental device}

Transparent PMMA material was employed so that the grout propagation could be observed. A great care was taken to follow exactly the same procedure for filling up all of the soil columns. Each soil column was firstly fully saturated by water from the bottom using a point source (Saiyouri et al., 2007, Chupin et al., 2007). Later, cement grout was slowly injected through the column. Cement grout transport evolution was controlled by monitoring the weight of the column, the pressure at different heights and effluent volumes with respect to time (Figure 1). Cement grout position was followed using CCD camera. 

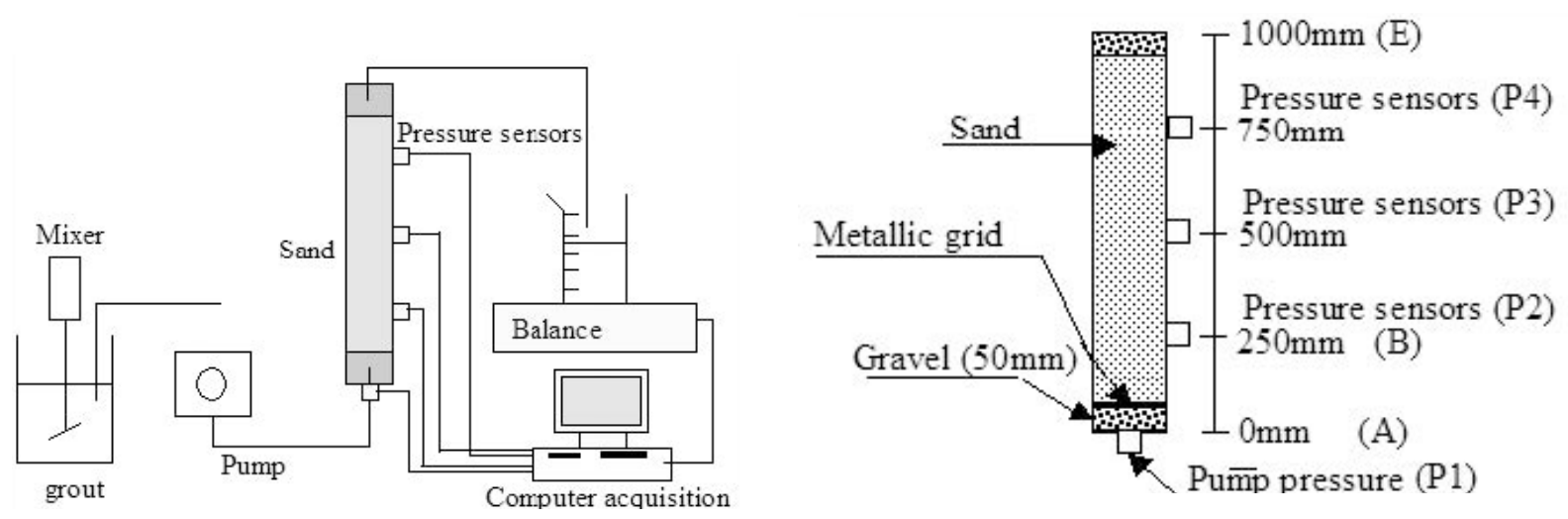

Figure 1. Schema of one dimensional laboratory cement grout injection experiment and column test details

\subsubsection{Specimen curing}

After injection, the injected sand column was placed in a climate chamber with a controlled environment of $20^{\circ} \mathrm{C}$ and $95 \%$ relative humidity during 28 days. The samples probed by gas permeability and MIP tests are cylinders of $50 \mathrm{~mm}$ of diameter and $50 \mathrm{~mm}$ height. They are cored from initial injected Loire sand columns then rectified to obtain a perfect geometry (two coplanar sections). Circumferential surface is sealed by a heat-shrinkable sleeve which prevents gas leakage during measurement and finally placed in a regulated oven for a pre- determined period until a constant weight is reached. The conventional temperature of the oven is quite high $\left(105^{\circ} \mathrm{C} \pm 5^{\circ} \mathrm{C}\right)$ for injected samples. For our specimens, it has some disadvantages, as micro cracking was induced into the specimen. We use therefore lower temperatures $\left(\sim 60^{\circ} \mathrm{C}\right)$, as a consequence, specimens had to be left drying for a longer than normal period to reach a constant weight.

\subsubsection{Gas test permeability}

Prior to gas permeability measurement, the specimen is removed from the drying oven and is left in a desiccator, placed at a temperature of $20^{\circ} \mathrm{C}$ for $48 \mathrm{~h}$. After this period, it is positioned in the Cembureau permeability cell shown in Figure 2 (Kollek, 1989).

The measurements of the apparent permeability were performed for at least four absolute injection pressures from: 0.1 , to $0.4 \mathrm{MPa}$. The applied pressures are adapted to the measurable upstream flow rate. They are usually chosen depending on the flow meter capacity. The injection flow rate is given by a digital thermal Mass Flow Meter (MFM) of ranges: 20-1000 $\mathrm{mln} / \mathrm{min}$. The atmospheric temperature and pressure are measured during the test with a digital thermo hygrobarometer. A period of 2 to $10 \mathrm{~min}$ approximately is necessary in order to reach the steady state gas flow. 


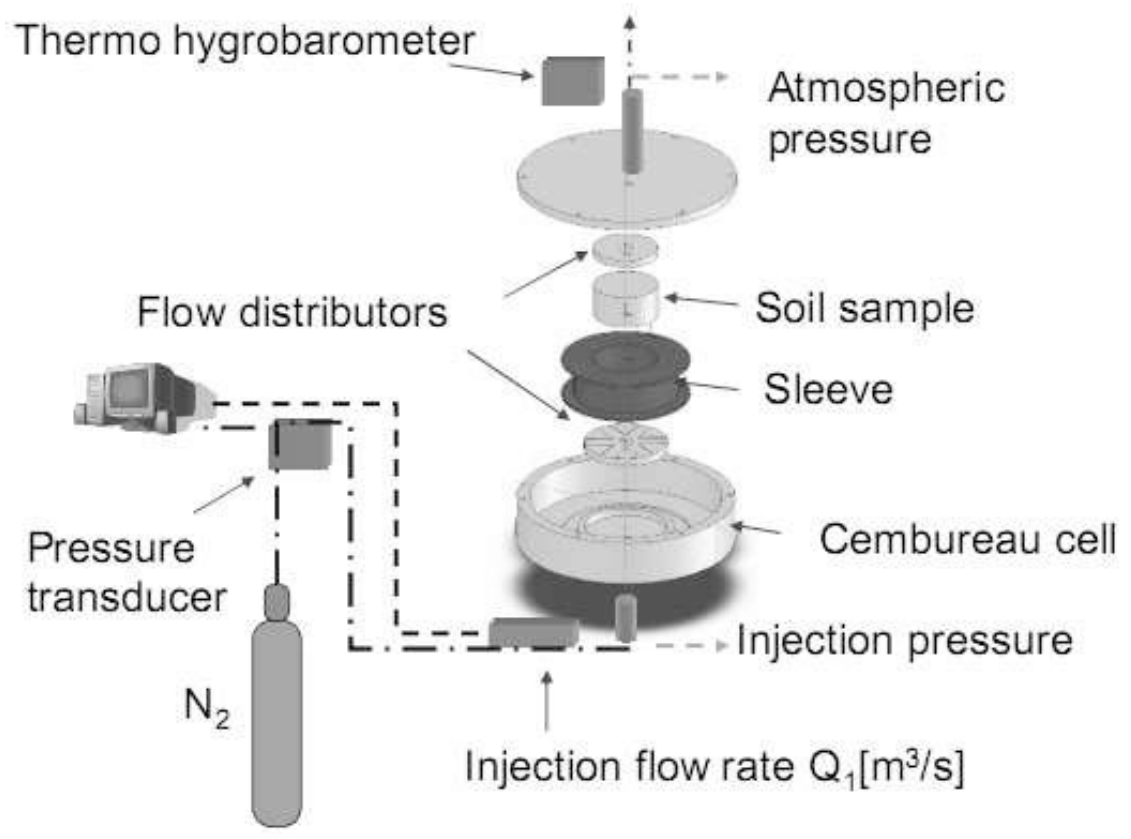

Figure 2. Schematic diagram of a Cembureau gas permeameter

\subsubsection{Mercury intrusion porosimetry tests}

After the permeability test, the specimen can be tested in a mercury porosimeter (Micromeritics $\rightarrow$ Autopore 9500) which can provide a maximum intrusion pressure of $414 \mathrm{MPa}$. Thus, only the pores whose diameters are between $3 \mathrm{~nm}$ and $360 \mu \mathrm{m}$ are accessible with this apparatus. We can deduce total porosity and the pore size distribution PSD of the tested samples.

\section{Gas flow throught porous media}

Kundt and Warburg (1875) who observed that the gas flow measured was higher than that calculated by Darcy's approach for a porous media. The mean free path of the gas molecules corresponds to the distance covered by a particle between two successive shocks. This distance depends on the pressure and the temperature. The mean pore size of the porous media was comparable with the mean free path of the gas molecules. This phenomenon is attributed to the discontinuous molecular structure of gases which gives place to a molecular slip flow near the wall of the pores (gas slippage theory). This flow, specific to gases is independent of the viscosity of the fluid and its contribution is all the more significant as the permeability of the medium is low (Klinkenberg, 1939). Indeed, its contribution in the total flow of gas becomes negligible when the diameter of the capillaries is much higher than the mean free path (viscous flow). Besides another limiting situation appears when this mean free path is much higher than the diameter of the capillary. This phenomenon is commonly well- known as "Knudsen flow" (Knudsen, 1909). The gas flow is mainly governed by diffusion phenomenon. Moreover in porous media gas molecules entering in collision with the wall of the pores remain thus 
adsorbed a certain time and are desorbed thereafter (Carman, 1956). Under any flow induced by a pressure gradient, a quantity of gas molecules is adsorbed on the pore surfaces. This one creates a gradient of concentration responsible for an additional diffusion flow. Fortunately the influence of this flow on the stationary mass and slip flow is often neglected because of the low volume of this adsorbed layer compared to total porous volume (Perraton, 1992).

\subsection{Gas permeability in porous media}

The total permeability of a porous medium will present various components, each one relative to a type of particular flow. The viscous flow is related to the intrinsic permeability concept $(\mathrm{Kv})$ and the nonviscous one which gathers the slip flow, Knudsen flow and diffusion flow.

\subsubsection{Generalised Darcy's law for compressible fluids}

For compressible fluids, the flow rate varies in any point with the pressure, even in stationary mode and the mass flow, $\mathrm{G}\left(\mathrm{kg} / \mathrm{m}^{2} \oplus \mathrm{s}\right)$, remains constant in any point:

$$
G=\rho v=-\frac{K_{v}}{\mu} \rho \frac{\partial P}{\partial x}
$$

with $\rho$ the fluid density $\left(\mathrm{Kg} / \mathrm{m}^{3}\right), \mu$ the dynamic viscosity (in $\mathrm{mPa} . \mathrm{sec}$ ).

If we integrate over the length of the sample and consider that viscosity is independent of the pressure and the ideal gas equation in an isothermal flow, we obtain the following relation [3], considering the relationship between density and pressure:

$$
\rho=\frac{M}{R T} P
$$

with $\mathrm{M}$ the fluid molar mass, $\mathrm{T}$ temperature and $\mathrm{R}$ gaz constant:

$$
\mathrm{v}=\frac{\mathrm{K}_{\mathrm{v}}}{\mu} \frac{\left(\mathrm{P}_{2}^{2}-\mathrm{P}_{1}^{2}\right)}{2 \mathrm{P}_{1} \mathrm{~L}}
$$

Moreover, gas transfer through a porous medium involves a dependence of the measured permeability with respect to the average pressure of flow. 
In gas permeability tests carried out on cement based materials, the flows are mainly viscous. It can be expressed by a linear relation between the apparent fluid speed and the applied gradient pressure $\left(\Delta \mathrm{P}^{2}\right)$ once the steady regime flow is reached for each test pressure. Nevertheless, such flows present a significant nonviscous flow component. Then it is necessary to exploit experimental measurements by defining an apparent permeability Ka which integrates this effect such as:

$$
K_{a}=\frac{2 \mu L P_{i n j} Q_{i n j}}{\left(P_{a t m}^{2}-P_{i n j}^{2}\right) S}
$$

with S: section of the sample $\left(\mathrm{m}^{2}\right), \mathrm{L}$ : thickness of the sample $(\mathrm{m}), \mathrm{Q}$ : injection flow rate measured at the exit of the test cell $\left(\mathrm{m}^{3} / \mathrm{s}\right)$. For Cembureau device, the $P_{\text {inj }}$ is equivalent to $\mathrm{P}_{1}$ and $\mathrm{P}_{\text {atm }}$ is the $\mathrm{P}_{2}$ one (in Equation [3]), both are expressed in Pascal.

From experimental results giving the apparent permeability, different concepts allow determining an intrinsic permeability related to a viscous flow in cement based medium.

From the $\mathrm{K}_{\mathrm{a}}$ values obtained with the various pressure gradient values, two approaches allow obtaining the intrinsic permeability value related to the viscous gas flow or gas mass flow.

\subsection{Theoretical approaches}

To estimate the intrinsic permeability we apply the two fundamental approaches developed by Klinkenberg and Carman.

\subsubsection{Klinkenberg approach}

Adzumi (1937a; 1937b) and later Klinkenberg (1939) deduced that the value of the permeability coefficient is independent of the nature of the fluid (liquid or gas) for very high pressure levels (the flow is then supposed to be purely viscous). Klinkenberg thus proposed the following general relation for the flow of a gas through a porous environment:

$$
\mathrm{K}_{\mathrm{a}}=\mathrm{K}_{\mathrm{v}}\left(1+\frac{\beta}{\mathrm{P}_{\mathrm{m}}}\right)
$$

with $\beta$ : coefficient of Klinkenberg, $\mathrm{P}_{\mathrm{m}}=\left(\mathrm{P}_{\mathrm{atm}}+\mathrm{P}_{\mathrm{inj}}\right) / 2$ : average pressure of flow (Pa). 
$\mathrm{K}_{\mathrm{V}}$ is inferred graphically by extrapolation to an infinite flow pressure. This means that when the inverse of the average pressure tends towards zero; the value of $\beta$, function of the porosity of the medium and infiltrating gas, is calculated directly starting from relation [5].

The advantage of this relation is the visualization of both the viscous and nonviscous part of the fluid flow (Figure 3a). This approach is limited by the permeability dependence of saturation degree of the specimen.

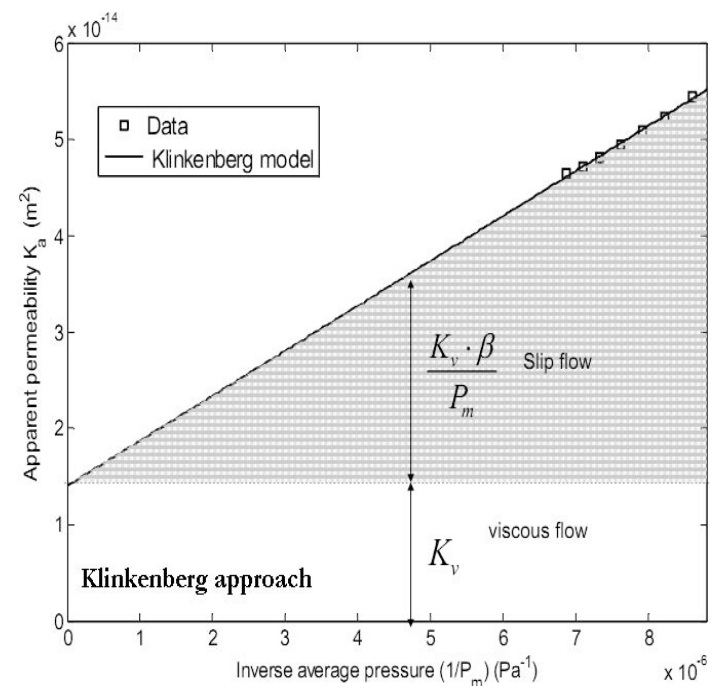

(a)

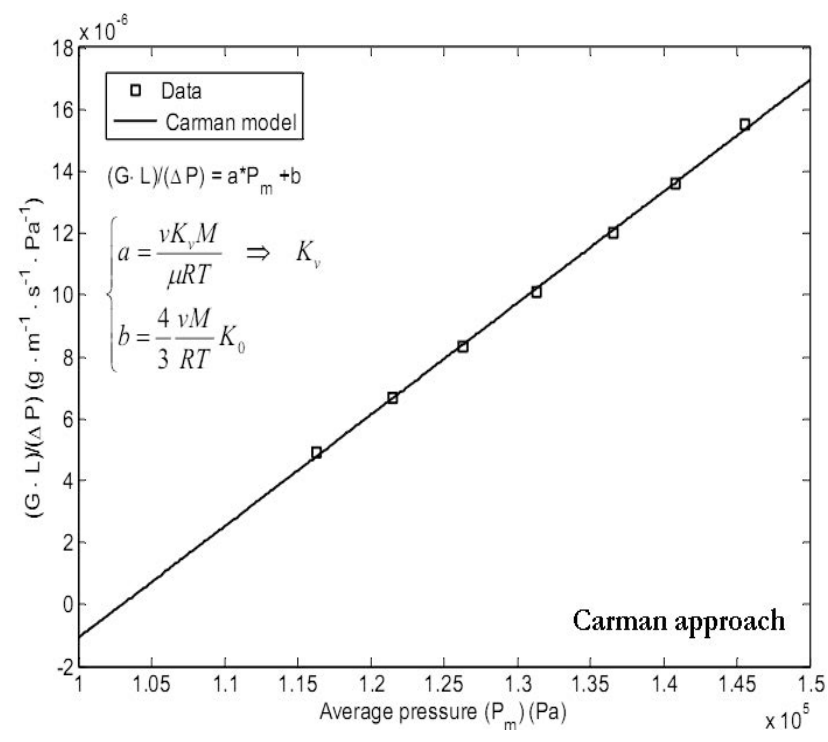

(b)

Figure 3. Graphical determination of intrinsic permeability

\subsubsection{Carman approach}

Carman et al. defined $\mathrm{K}_{\mathrm{ad}}, \mathrm{K}_{\mathrm{V}}$ and $\mathrm{K}_{0}$ respectively as the permeability coefficient related to the diffusion phenomena, the permeability coefficient which governs the mass flow and the one which characterizes molecular flow. They proposed a formulation which allows evaluating intrinsic permeability (Carman and Malherbe, 1950), assuming an isothermal flow:

$$
\frac{v P L}{\Delta P}=K_{a d}+\frac{K_{v}}{\mu} P_{m}+\frac{4}{3} K_{0} \bar{v}
$$

where $\mathrm{P}_{\mathrm{m}}=\left(\mathrm{P}_{\mathrm{atm}}+\mathrm{P}_{\text {inj }}\right) / 2$, is the average pressure of flow $(\mathrm{Pa})$, and the molecular mean velocity defined by:

$$
\bar{v}=\sqrt{\frac{8 R T}{\pi M}}
$$


with M: molecular mass $(\mathrm{g} / \mathrm{mol}), \mathrm{T}, \mathrm{R}$ : temperature $(\mathrm{K})$ and ideal gases constant respectively.

Oxygen, nitrogen or hydrogen are not wetting fluids, therefore the surface diffusion flow can be neglected, it leads to:

$$
\frac{v_{i n j} P L}{\Delta P}=\frac{K_{v}}{\mu} P_{m}+\frac{4}{3} K_{0} \bar{v}
$$

We notice that the Equation [9] is valid for all the types of porous media, with all the fluid types. It is thus of a great interest. The Carman approach which leads to the value of $K_{V}$ is based on the concept of mass flow rate per unit area $G$ and ideal gas state equation:

$$
\mathrm{G}=\rho \mathrm{v}=\frac{\mathrm{PM}}{\mathrm{RT}} \mathrm{v}
$$

where $\mathrm{r}$ is the density, $\mathrm{v}$ is the velocituy of flow, $\mathrm{P}$ the pressure, $\mathrm{M}$ the molecular mass, $\mathrm{R}$ ideal gaz constant and $\mathrm{T}$ temperature:

Relation [9] can be written as:

$$
\mathrm{G} \frac{\mathrm{L}}{\Delta \mathrm{P}}=\mathrm{aP}_{\mathrm{m}}+\mathrm{b}
$$

The coefficients $\mathrm{a}$ and $\mathrm{b}$ are the Carman's constants:

$$
\begin{aligned}
& \mathrm{a}=\frac{\mathrm{K}_{\mathrm{v}} \mathrm{M}}{\mu \mathrm{RT}}\left(\mathrm{gm}^{-1} \mathrm{~Pa}^{-2} \mathrm{~s}^{-1}\right) \\
& b=\frac{4}{3} \frac{\bar{v} M}{R T} K_{0}\left(\mathrm{gm}^{-1} \mathrm{~Pa}^{-1} \mathrm{~s}^{-1}\right)
\end{aligned}
$$

Carman showed that we could determine $\mathrm{K}_{\mathrm{v}}$ graphically and $\mathrm{K}_{0}$ using a linear regression between $\mathrm{G}$ and $\mathrm{P}_{\mathrm{m}}$ (Figure 3b). Perraton (1992) used successfully this experimental approach with the cases of concrete and mortar which were homogenised media.

Concerning our study, we will show that there is equivalence between the two distinct approaches previously described for grouted sand. 


\section{Mercury intrusion porosimetry}

An analytical technique useful for determining the pore size distribution and thus understanding the structure of pore systems in the porous media is capillary pressure analysis. Pore systems consist of pores and smaller channels (pore throats) connecting the pores. Pore throats, in conjunction with pore-system geometry and topology control the movement of fluids between pores. Through the use of capillary pressure curves derived from mercury-injection porosimetry, it is possible to calculate pore size and distribution.

Mercury-injection porosimetry (MIP) is based on measurement of volume distribution of pore throats; the method depends on forcing mercury into small voids, pore throats, within the porous media. Pore throats control access to larger voids (pores) because greater pressures are required to force mercury or other nonwetting fluids into smaller spaces (Purcell, 1949). Thus, pore throats are bottlenecks in the system, and it is necessary to exceed their critical capillary pressure in order to inject mercury into pores. Mercury is injected at incrementally higher pressures. Equilibrium time is necessary between pressure increments; mercury is injected into increasingly smaller pores. It is then possible to calculate the size distribution of pore throats assuming that soil pores are cylindrical flow channels; Jurin's equation (Washburn, 1921) is used to determine the pore radius associated with each mercury pressure increment:

$$
\mathrm{p}=(4 \sigma / \mathrm{D}) \cos (\theta)
$$

where $\mathrm{D}$ is the entrance pore diameter $(\mathrm{m})$, $\int$ the surface tension of the liquid $\left(0.485 \mathrm{~N} \mathrm{~m}^{-1}\right.$ for mercury), ( the contact angle of fluid interface to solid $\left(140^{\circ}\right.$ is an average value for mercury-air interface as suggested by Penumadu and Dean (2000), and $\mathrm{p}$ the mercury pressure increment $(\mathrm{Pa})$.

The results were plotted in two graphical forms. In the first form, the cumulative pore volume was plotted versus logarithmically space, and in the second form the differential PSD based on the logarithmic differentiation $\mathrm{dV} / \mathrm{d} \log \mathrm{D}$ was calculated (Figure 4). Both forms of presentation have the same unit $\left(\mathrm{cm}^{3} \oplus \mathrm{g}^{-1}\right)$ and therefore can be directly compared. This approach where various methods are combined is seldom used to characterize a pore system over a wide range of pore radii in relation to soil management practices, but it was useful in describing the differences in pore structure between different soil types (Hajnos, 1998).

\subsection{Evaluation of intrinsic permeability by Katz-Thompson theory}

There have been many attempts over the years to relate permeability to some relevant microstructurally defined length scale. Katz and Thompson (1986) provide an important contribution to mass transport studies in facilitating the 
predictions of fluid permeability of materials from mercury injection data. The equations were derived from percolation theory (Tumidajski and Lin, 1998).

The first équation provided rigorous results by incorporating the measured conductivity formation factor (conductance ratio) $\sigma / \sigma_{0}$ as a parameter. The equation for permeability is:

$$
\mathrm{k}=\frac{1}{226} 1_{\mathrm{c}}^{2} \frac{\sigma}{\sigma_{0}}
$$

where $1_{c}$ is the characteristic pore diameter of the porous medium which is the smallest pore diameter necessarily filled to initiate a flow through the porous medium, $\sigma$ is the rock conductivity at characteristic pore length $1_{c}$, and $\sigma_{0}$ the conductance of brine in the pore space.

The second equation provides for an estimation of $\sigma / \sigma_{0}$ to be obtained from the same mercury intrusion data as were used to determine $\mathrm{k}$.

$$
k=\frac{1}{226} l_{c}^{2} \frac{l_{\max }}{L_{c}} n S\left(l_{\max }\right), l_{\max }=0.34\left(l_{c}\right)
$$

It is widely accepted that permeability is determined by microstructure. A large number of models have been developed, particularly for sedimentary rocks, to predict the permeability from measurements of pore structures and cracks [3]-[12]. For cementitious materials, it is well recognized that both total porosity and its distributions determine the permeability, and that only pores with diameters greater than a specific value contribute significantly to permeability [16].

As the pressure is increased, mercury is forced to invade smaller and smaller pore openings in the permeable medium. Ultimately, a critical pressure is reached at which the mercury spans the sample. This conduction path is composed of pores of diameter equal to and larger than the diameter calculated from the Washburn equation for the critical pressure. This diameter $1_{c}$ in Equation [14] is a unique transport length scale and dominates the magnitude of the permeability. To obtain this characteristic length $l_{c}$ from the mercury intrusion data set, pressure is determined at the point of inflection in the rapidly rising range of the cumulative intrusion curve. 


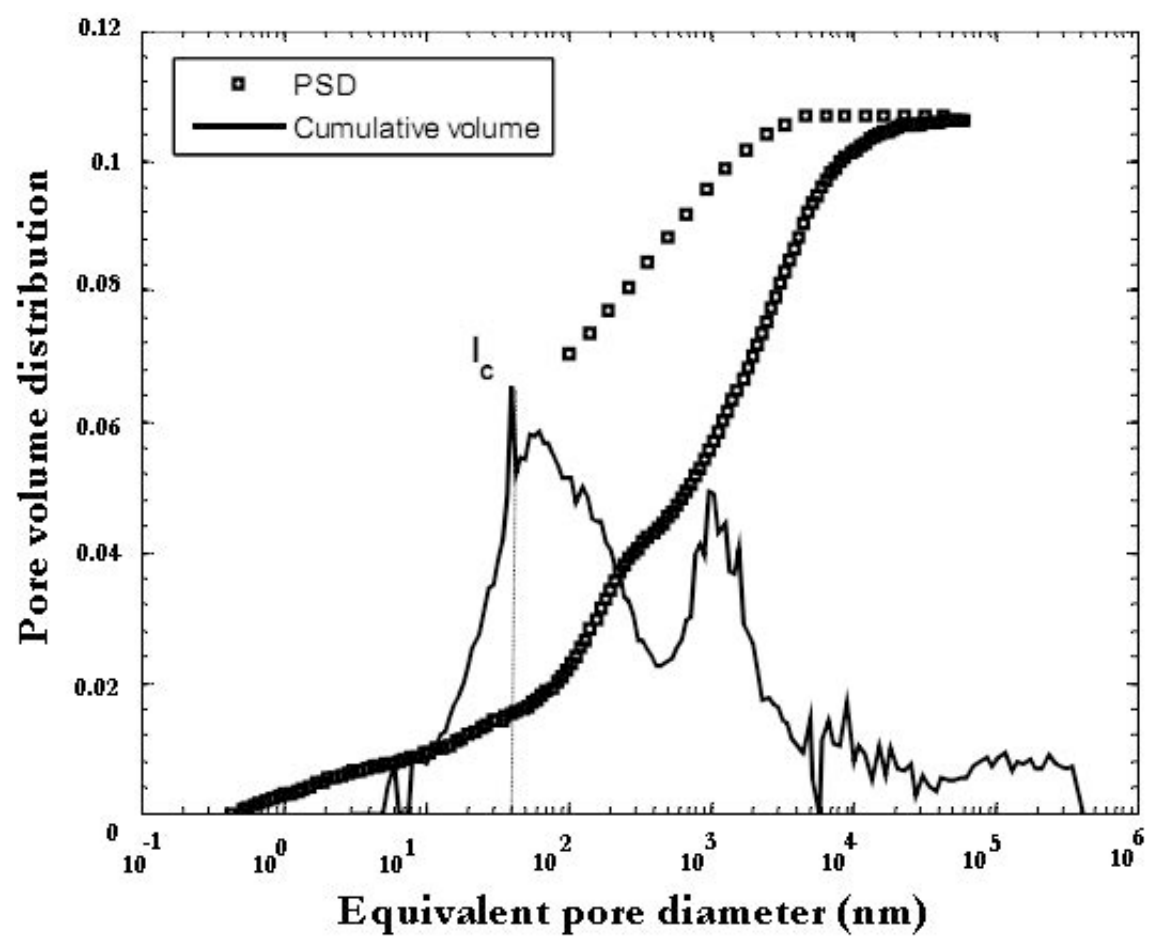

Figure 4. Characteristic pore diameter of the porous medium lc

This inflection point was determined experimentally by Katz and Thompson to correspond closely to the pressure at which mercury first spans the sample and the point at which percolation begins. The value of $l_{c}$ is the pore diameter calculated from the Jurin's equation (Figure 4).

\section{Results and discussion}

\subsection{Gas permeability comparison}

Comparison of the permeability values obtained using Carman and Klinkenberg approaches with those obtained using the isothermal steady flow is shown in Figures 5 and 6 . Values of predicted permeabilities by both methods are similar, with maximum difference of only 0.3 units (Figure 7 ) and reported in Table 3. This means that the steady-state approach provides an easy and fast method to determine permeability. However, the method is limited by the length of the dataset. If the dataset is too short, transient effects may become more significant. It reflects a leakage of separation between laminar and turbulent flow along the sample. 


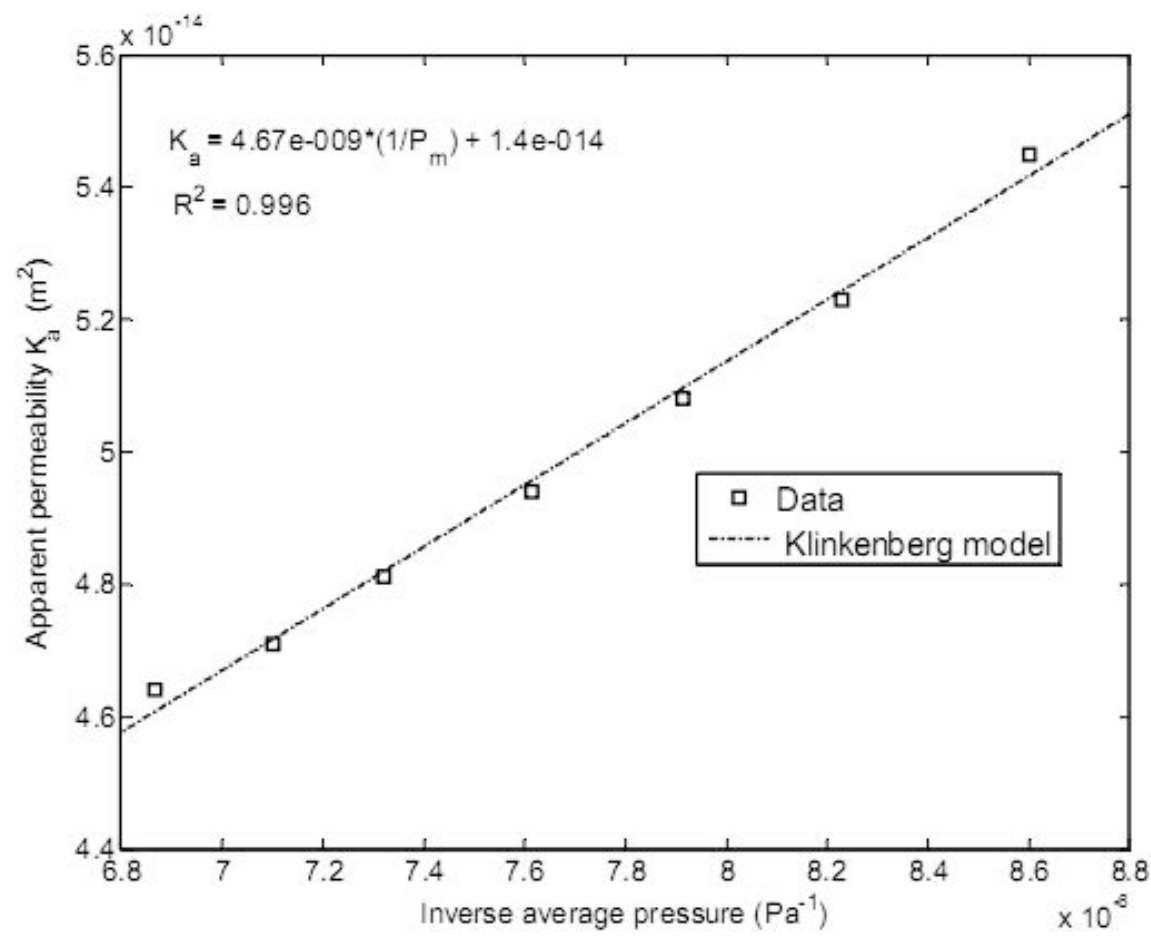

Figure 5. Example of application of the Klinkenberg approach obtained on sample 1C1

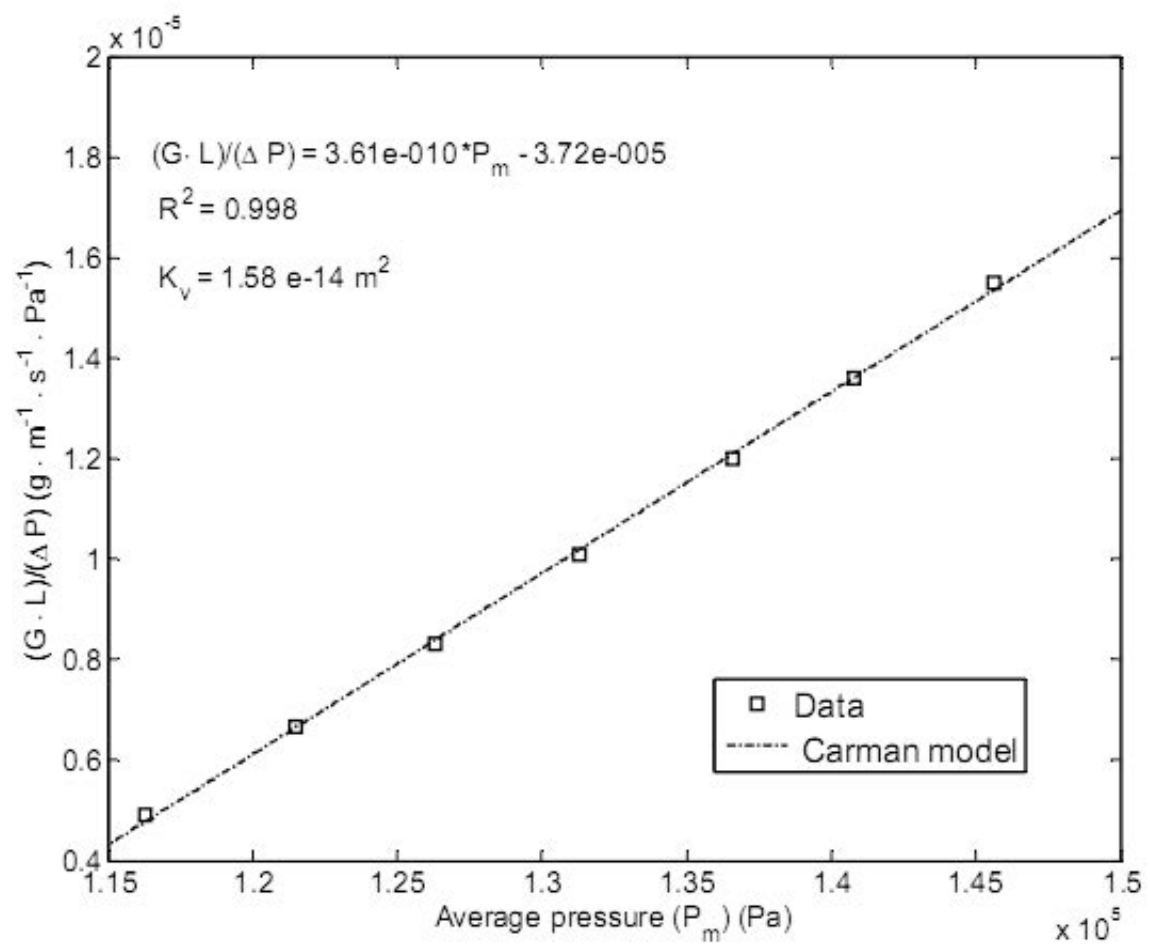

Figure 6. Example of application of the Carman approach obtained on sample 1C1

We can notice that Carman approach leads to a better correlation between mass flow rate and the average pressure. 


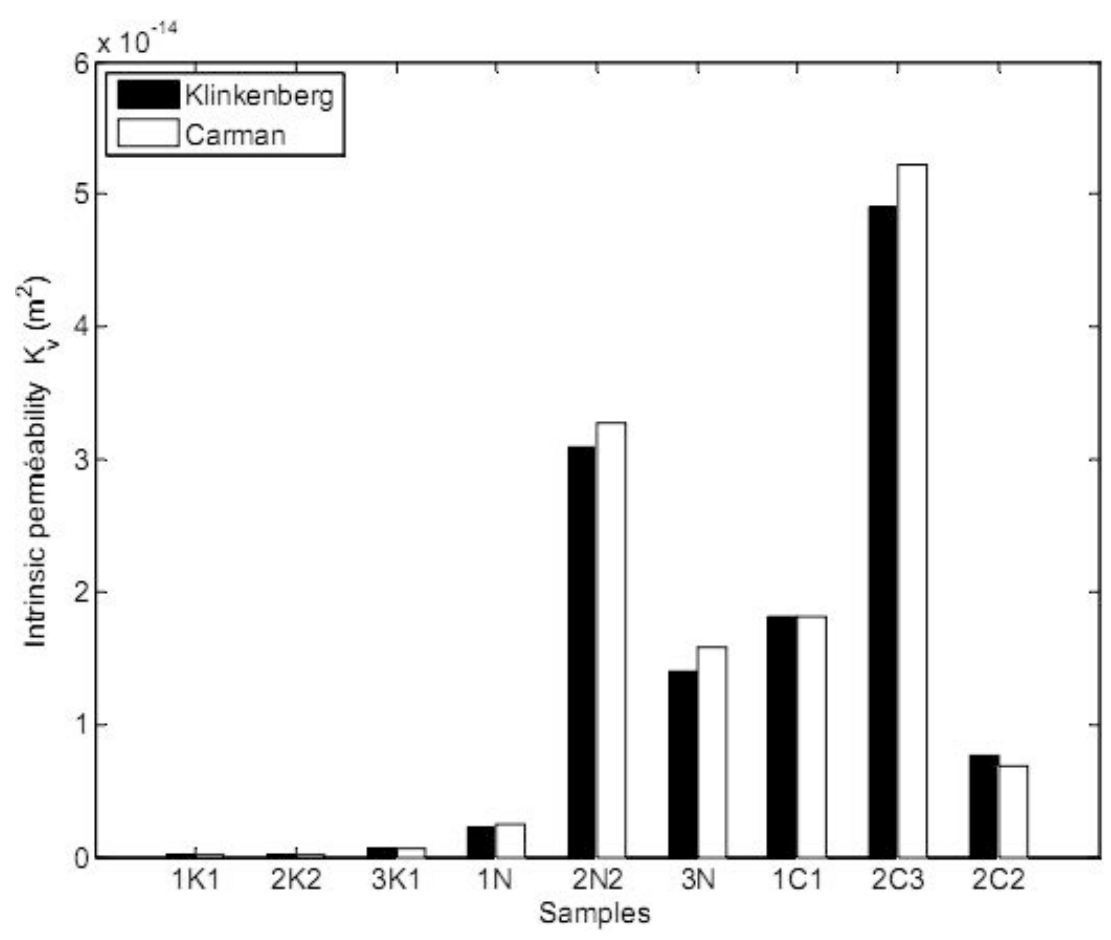

Figure 7. Comparison between Klinkenberg and Carman approaches on injected samples

For this experimental setup a series of calculation errors may arise from: (1) measurement of the sample geometry and the gas flow rate, (2) technical equipment (pressure transducer), (3) conversion of the transducers raw data (voltage) into pressure data $(\mathrm{Pa}),(4)$ factors that are not accounted in the non 1D flow effects, and the different forms of non-linear friction laws that are possible. An estimation of the practical precision of these experiments, repeated ten times under the same external conditions, indicates a precision of $2-5 \%$ for the permeability values $\mathrm{K}$ using at least four different pressures for each method. For most of the injected soils the investigation of samples revealed significant difference in the permeability values with respect to $\mathrm{C} / \mathrm{W}$ ratio. For these soil samples that have close initial densities, the intrinsic permeability is inversely proportional to the $\mathrm{C} / \mathrm{W}$ ratio. Indeed, low initial densities increase the formation of localized cement micro aggregates, thus induce low permeability.

\subsection{Porous network of grouted sand}

Table 2 presents for some samples of grouted soils the conductivity before injection $(\mathrm{K})$, the conductivity after grout injection $\mathrm{K}_{\mathrm{k}}$ and $\mathrm{K}_{\mathrm{c}}$ (respectively according Katz and Caman approaches) and also porosities before and after injection respectively, $\mathrm{n}_{0}$ and $\mathrm{n}_{\mathrm{f}}$. This table shows porosity variation with respect to the density and the $\mathrm{C} / \mathrm{W}$ ratio. We can notice that when the density increases, the final porosity $\left(\mathrm{n}_{\mathrm{f}}\right)$ increases also. Furthermore, this later is lower when the $\mathrm{C} / \mathrm{W}$ increases. Actually, filling void space of the medium by the grout is all the more difficult as the initial density is high. But if the initial density is weak, the 
void filling by cement particles is important when the grout is more concentrated. Besides, Figure 8 presents the porosity spectrum which reveals two main pore classes delimited by the following poral diameters $0.4 \mu \mathrm{m}$ and $6 \mu \mathrm{m}$ (Bruand and Cousin, 1995; Dubinin, 1979):

- Microporosity: pores whose diameter is lower than $0.4 \mu \mathrm{m}$, which characterize the fine phase of the injected sand due to fine component agglomerations;

- Mesoporosity: pores between $0.4 \mu \mathrm{m}$ to $6 \mu \mathrm{m}$ due to the assembly of coarse elements and micro-aggregates.

Table 2. Parameters of injected samples

\begin{tabular}{|c|c|c|c|c|c|c|c|c|c|}
\hline Reference & $1 \mathrm{~K} 1$ & $2 \mathrm{~K} 2$ & $3 \mathrm{~K} 1$ & $1 \mathrm{~N}$ & $2 \mathrm{~N} 2$ & $3 \mathrm{~N}$ & $1 \mathrm{C} 1$ & $2 \mathrm{C} 3$ & $2 \mathrm{C} 2$ \\
\hline$\gamma_{\mathrm{d}}\left(\mathrm{KN} / \mathrm{m}^{3}\right)$ & 17,24 & 17,24 & 17,24 & 17,3 & 17,3 & 17,3 & 18,03 & 18,03 & 18,03 \\
\hline $\mathrm{C} / \mathrm{W}$ & 0,42 & 0,42 & 0,42 & 0,28 & 0,28 & 0,28 & 0,42 & 0,42 & 0,42 \\
\hline $\mathrm{K}\left(10^{-11} \mathrm{~m}^{2}\right)$ & 2,53 & 2,53 & 2,53 & 2,51 & 2,51 & 2,51 & 1,93 & 1,93 & 1,93 \\
\hline $\mathrm{K}_{\mathrm{k}}\left(10^{-16} \mathrm{~m}^{2}\right)$ & 1,33 & 1,47 & 6,28 & 22,7 & 104 & 310 & 140 & 490 & 76,87 \\
\hline $\mathrm{K}_{\mathrm{c}}\left(10^{-16} \mathrm{~m}^{2}\right)$ & 1,44 & 2,1 & 6,67 & 24,3 & 111 & 328 & 158 & 523 & 68,55 \\
\hline $\mathrm{n}_{0}(\%)$ & 34,2 & 34,2 & 34,2 & 34 & 34 & 34 & 31,2 & 31,2 & 31,2 \\
\hline $\mathrm{n}_{\mathrm{f}}(\%)$ & 20,6 & 20,4 & 20,1 & 26,8 & 27,2 & 25,6 & 21,7 & 21,8 & 21,8 \\
\hline
\end{tabular}

In all the cases, we notice a typical bimodal porosity spectrum. It characterizes finely aggregated media when $\mathrm{C} / \mathrm{W}$ ration is weak (Figure 8) and microagregated media for high charged cement grout (Figures 9 and 10). We can also highlight that the mesoporosity disappears in favour of microporosity when the initial dry density of the injected soil grows.

Figure 10 shows a clear bimodal regime. For Figures 8 and 9, the curves are slightly different and the two modes are less obvious. This can be due to the heterogeneity which can occur during the soil grouting operations.

Several authors (Bruand and Cousin, 1995) indicated that such samples, with this typical porosity spectrum, represent a complex porous network (Hajnos, 1998). Consequently, the interpretation of the distributions calculated by the Washburn model, containing various significant pores does not match to the gas permeability measurements. It means that total porosity is underestimated by measurement. 


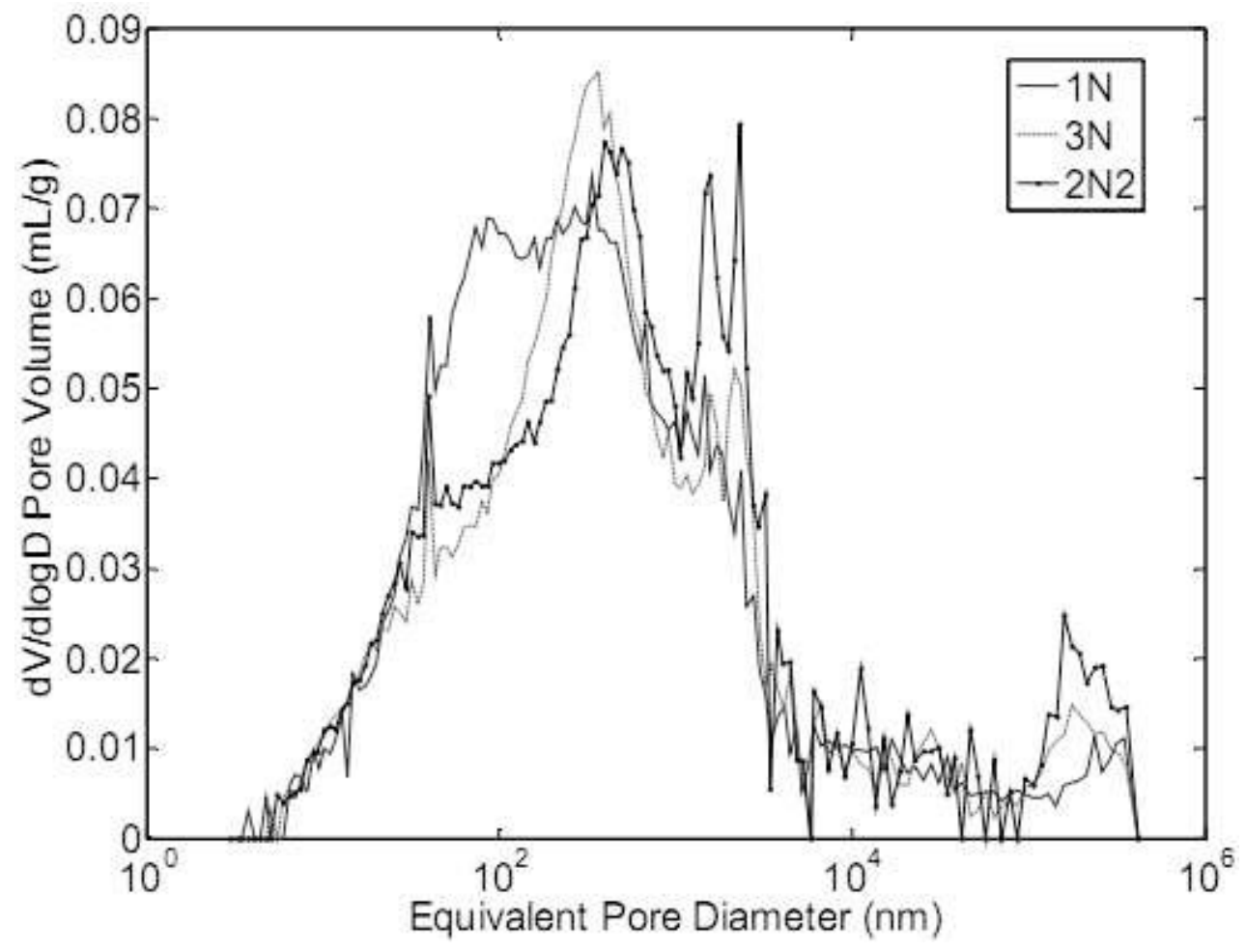

Figure 8. $\gamma_{d}=17.3 \mathrm{KN} / \mathrm{m}^{3}, C / W=0.28$

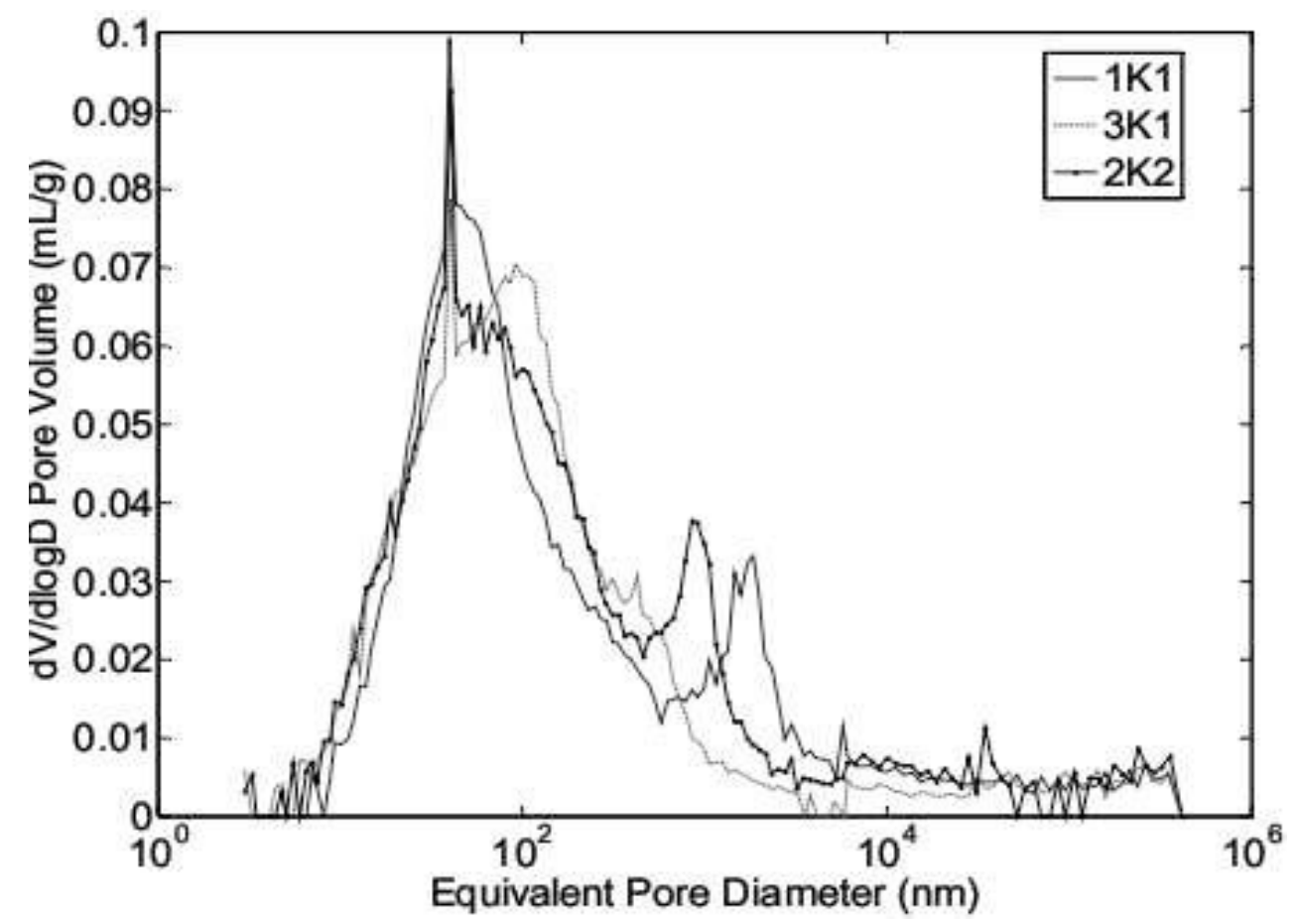

Figure 9. $\gamma_{d}=17.24 \mathrm{KN} / \mathrm{m}^{3}, C / W=0.42$ 


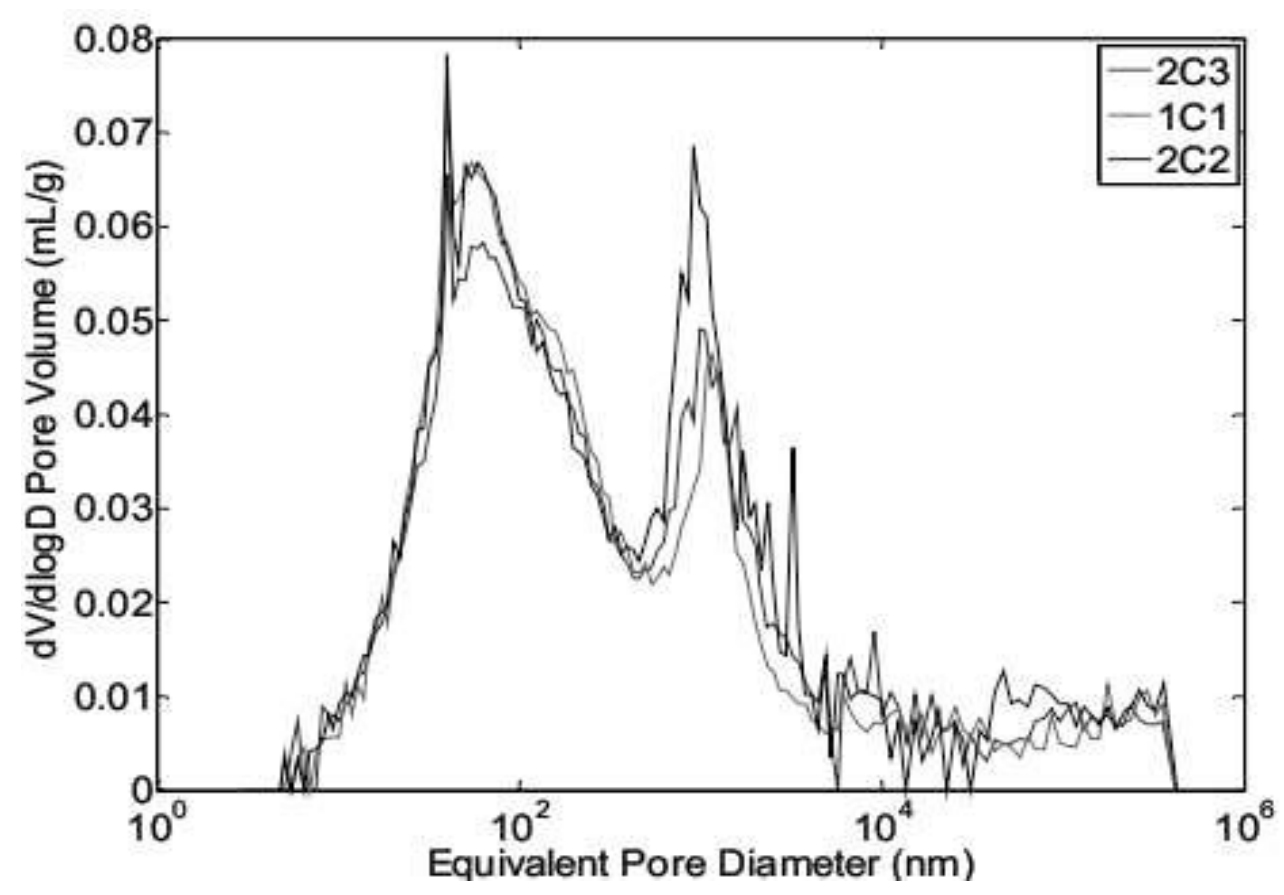

Figure 10. $\gamma_{d}=18.03 \mathrm{KN} / \mathrm{m}^{3}, C / W=0.42$

\subsection{Gas permeability estimation}

Table 3 presents the results of the permeability calculation using KatzThompson formulation $\left(\mathrm{K}_{\text {calc }}\right)$ and those measured by the gas permeability (Kmes). Finally we observed that the measured gas permeability is three times more than the calculated $\left(\mathrm{K}_{\text {calc }}\right)$ based on MIP tests (Table 3$)$. The main advantage of the Katz-Thompson formulation is that the time required to make these measurement is much shorter, and much less labour intensive than is required to make traditional permeability tests. Besides, it allows specimens of any composition and/or age to be evaluated. Unfortunately we noticed that permeabilities calculated using the Katz-Thompson equation (Equation [15]) does not correspond to the experimental data for this type of material.

By comparison of different PSD of the network and evaluating the corresponding effect on gas flow, corrected factors between pore structure and transport properties can be established. To improve this prediction, we derive Equation [15] from Katz-Thompson formulation to include the initial density effect over intrinsic permeability substituting the ratio $\frac{1_{\max }}{1_{c}} . S\left(1_{\max }\right)$ which includes porous network connectivity by $10^{2-\frac{\gamma_{d}}{\gamma_{\max }}} \mathrm{S}\left(1_{\mathrm{c}}\right)_{\mathrm{y}}$. This modification allows taking mesoporosity reduction while initial density increases. We obtain the following new expression: 


$$
\mathrm{K}=\frac{1}{226} 1_{\mathrm{c}}^{2} 10^{2-\frac{\gamma_{\mathrm{d}}}{\gamma_{\max }}} \mathrm{nS}\left(1_{\mathrm{c}}\right)
$$

where $1_{c}$ is the characteristic pore diameter of the porous medium, $\gamma_{d}$ is the initial apparent density, $\gamma_{\max }$ is the maximal initial density obtained using NF P 94-059 standard, $\mathrm{n}$ is total porosity and $\mathrm{S}$ is the fraction of total porosity filled at $\mathrm{l}_{\mathrm{c}}$.

Most approaches are based on fitting this parameter of the network model to experimentally measured transfer and pore parameters. This kind of approach, however, does not result in a network able to represent the realistic microstructure of cement-based materials, because the connectivity of the pore network is not so simple that it can be controlled by only one or two parameters. However it can be inferred from the experiments that the connectivity of the pore structure and the characteristic pore diameter are the main factors, which determine the permeability.

Table 3 shows the intrinsic permeability $\mathrm{K}_{\mathrm{m}}$ calculated by the modified KatzThompson formulation. Using this enhancement, we can obtain the same order of magnitude between calculated and measured conductivity values. For some samples, this model failed because of local heterogeneities of grouting process which are commonly observed.

Table 3. Intrinsic permeability of injected samples

\begin{tabular}{|c|c|c|c|c|c|c|c|c|c|}
\hline Reference & $1 \mathrm{~K} 1$ & $2 \mathrm{~K} 2$ & $3 \mathrm{~K} 1$ & $1 \mathrm{~N}$ & $2 \mathrm{~N} 2$ & $3 \mathrm{~N}$ & $1 \mathrm{C} 1$ & $2 \mathrm{C} 3$ & $2 \mathrm{C} 2$ \\
\hline$\gamma_{\mathrm{d}}\left(\mathrm{KN} / \mathrm{m}^{3}\right)$ & 17,24 & 17,24 & 17,24 & 17,3 & 17,3 & 17,3 & 18,03 & 18,03 & 18,03 \\
\hline $\mathrm{C} / \mathrm{W}$ & 0,42 & 0,42 & 0,42 & 0,28 & 0,28 & 0,28 & 0,42 & 0,42 & 0,42 \\
\hline $\mathrm{l}_{\mathrm{c}}(\mathrm{nm})$ & 40 & 40 & 40 & 337 & 393 & 364 & 40 & 40 & 40 \\
\hline $\mathrm{K}_{\text {mes }}\left(10^{-16} \mathrm{~m}^{2}\right)$ & 1,33 & 1,47 & 6,28 & 22,7 & 104 & 310 & 140 & 490 & 76,87 \\
\hline $\mathrm{K}_{\text {cal }}\left(10^{-19} \mathrm{~m}^{2}\right)$ & 4,81 & 4,93 & 4,61 & 316 & 469 & 385 & 5,11 & 5,11 & 5,46 \\
\hline $\mathrm{K}_{\mathrm{m}}\left(10^{-16} \mathrm{~m}^{2}\right)$ & 442 & 121 & 26 & 56 & 137 & 970 & 279 & 264 & 1893 \\
\hline
\end{tabular}

\section{Conclusion}

This paper presents an intrinsic permeability measurement using CEMBUREAU gas permeameter apparatus. Two fundamental approaches currently admitted for cement based materials are used to interpret the results. These two formulations lead to similar intrinsic permeability values of grouted Loire sand samples. This comparison proved that Klinkenberg approach, which is easier to use than Carman approach can be employed without restrictions to evaluate this 
transfer property. We can also achieve a considerable reduction in measurement time with this type of device. In addition to this apparatus, MIP tests can also be used to broadly estimate the permeation of grouted sand samples by simply applying Katz- Thompson theory. A modification of this formulation taking into account a corrective term related to the initial density effect allows obtaining the correct order of magnitude of the intrinsic permeability. The limitations of MIP measurements make difficult to estimate transfer properties. Indeed only interconnected pores available for gas flow must be considered to evaluate intrinsic permeability. Therefore this contribution should be studied using a better description of pore size distribution (pore structure) across a wider range of pore sizes. Therefore additional methods such as nitrogen sorption and/or water desorption could be coupled to MIP to have better results.

\section{References}

Abbas A., Carcassès M., Ollivier J.-P., "Gas permeability of concrete in relation to its degree of saturation”, Mater. Struct., vol. 32, n 3-8, 1999.

Adzumi, H., "Studies on the flow of gaseous mixtures through capillaries: I. The viscosity of binary gaseous mixtures", Bull. Chem. Soc., Japan, vol. 12, 1937a, p. 99-226.

Adzumi H., "Studies on the flow of gaseous mixtures through capillaries: II. The molecular flow of gaseous mixtures", Bull. Chem. Soc., Japan, vol. 12, 1937b, p. 285-291.

AFREM, Durabilité des bétons, Essai de perméabilité aux gaz du béton durci: mode opératoire recommandé, 1996.

American Petroleum Institute: API Recommended Practice for Determining Permeability of Porous Media, RP-27, Dallas, TX, 1956.

Arenzana L.M., An experimental investigation of the properties and be- havior of dilute microfine cement grouts, Thèse de doctorat, Northwestern University, USA, 1987.

ASTM, ASTM D4525-04 Standard Test Method for Permeability of Rocks by Flowing Air 2004, Bamforth P.B., The relationship between permeability coefficients for concrete obtained using liquid and gas, Mag. Concr. Res., vol. 39, n 138, 1987, p. 3-11.

Basheer P.A.M., Long A.E., Montgomery F.R., The Autoclam - a new test for permeability, Concr., 1994, p. 27-29.

Bruand A., Cousin I., "Variation of textural porosity of a clay-loam soil during compaction", Eur. J Soil Sci., vol. 46, 1995, p. 377-385.

Cabrera J.G., Lynsdale C.J.,"A new gas permeameter for measuring the permeability of mortar and concrete", Mag. Concr. Res., vol. 40, nº 144, 1988.

Carman P.C., Flow of gases through porous media, London: Butterworths scientific publications, London, 1956. 
Carman P.C., Malherbe P. le R., "Diffusion and flow of gases and vapours through microrpores", II, Surface Flow, Proc. of Royal Society of London, Serie A, Mathematical and physical sciences, vol. 203, 1950, p. 165-178.

Chupin O., Saiyouri N., Hicher P.-Y., "The effects of filtration on the injection of cementbased grouts in sand columns", Transport in Porous Media, vol. 72, 2007, p. 227-240.

Claisse P.A., Ganjian E., Adlam T.A., "A vacuum permeability test for in situ assessment of cover concrete", Cem. Concr. Res., 2003, p. 3347-53.

Claisse P.A., Ganjian E., Atkinson A., Tyrer M., "Measuring and predicting transport in composite cementitious barriers", ACI Mater. J., vol. 103, n 2, 2006, p. 113-120.

Dhir R.K., Hewlett P.C., Byars E.A., Shaaban I.G., "A new technique for measuring the air permeability of near-surface concrete source", Mag. Concr. Res., vol. 47, n 171, 1995, p. 167-176.

Dubinin M.M., "In characterization of porous solids", Sing, K. S. W. (Ed.), Soc. Chem. Indus., London, vol. 1, 1979, p. 1-11.

Figg J.W., "Methods of measuring the air and water permeability of concrete", Mag. Concr. Res., vol. 25, $\mathrm{n}^{\circ} 85,1973$, p. 213-219.

Hajnos M., "Mercury intrusion porosimetry as compared to other methods characterizing microstructure of soil materials", Zesz. Problemowe Postępów Nauk Roln, n 461, 1998, p. 523-537.

Katz A.J., Thompson A. H., "Quantitative prediction of permeability in porous rock", Phys. Rev. B: Condens. Matter, vol. 34, 1986, p. 8179-8191.

Klinkenberg L.J., The permeability of porous media to liquids and gases, Production Practice, Bataafsche Petroleum Maatschappij (Amsterdam - The Netherlands) and Shell Development Company, Emeryville, California, 1939, p. 200-213.

Knudsen M., Die gesetze der molecularströmung and der inneren reibungsströmungedr gase durch röhren", Annalen der Physik, vol. 34, 1909, p. 75-130.

Kollek J.J., "The determination of the permeability of concrete to oxygen by the Cembureau method - a recommendation", Mater. Struct., vol. 22, 1989, p. 225-230.

Kundt A., Warburg E., "On friction and thermal conductivity in rare gases", Philos. Mag., vol. $50, \mathrm{n}^{\circ} 53,1875$.

Lydon F.D., "The relative permeability of concrete using nitrogen gas", Construct. Build. Mater., vol. 7, n 4, 1993, p. 213-220.

Martin G.R., "A method for determining the relative permeability of concrete using gas", Mag.Concr. Res., vol. 38, n 135, 1986, p. 90-94.

Monlouis-Bonnaire J.P., Verdier J., Perrin B., "Prediction of the relative permeability to gas flow of cement based materials", Cem. Concr. Res., vol. 34, n 5, 2004, p. 737-744.

Nonveiller E., Grouting : theory and practice, Elsevier, 1989. 
Penumadu D., Dean J., "Compressibility effect in evaluating the pore-size distribution of Kaolin clay using mercury intrusion porosimetry", Can. Geotech. J., vol. 37, n 2, 2000, p. 393-405.

Perraton D., La perméabilité aux gaz des bétons hydrauliques, INSA de Toulouse, 1992.

Purcell W.R., "Capillary-pressures - Their measurement using mercury and the calculation of permeability therefrom: American Institute of Mining, Metallurgical, and Petroleum Engineers", Petro. Trans., n 186, p. 39-48, 1949.

Saiyouri N., Bouasker M., Khelidj A., "Gas permeability measurement on injected soils with cement grout", Cement and Concrete Research (CCR), vol. 38, n 1, 2007, p. 95-103.

Schwarz L.G., Krizek R.J., "Effect of preparation technique on permeability and strength of cement-grouted sand", Geotechnical Testing Journal, vol. 17, n 4, 1994, p. 434-443.

Tumidajski P.J., Lin B., "On the validity of the Katz-Thompson equation for permeabilities in concrete", Cem. Concr. Res., vol. 28, n 5, 1998, p. 643-647.

Verdier J., Carcassès M., "Modelling of a gas flow measurement: application to nuclear containment vessels", Cem. Concr. Res., vol. 32, n 8, 2002, p. 1331-1340.

Washburn E.W., "The dynamics of capillary flows”, Phys. Rev., 1921, p. 273-283.

Zebovitz S., Krizek R.J., Atmazidis D.K., "Injection of fine sands with very fine cement grout", Journal of Geotechnical Engineering Div., 115, 12, 1989, p. 1717-1733. 